\title{
Immunization with thyroglobulin induces Graves'-like disease in mice
}

\author{
Toyoshi Endo* and Tetsuro Kobayashi* \\ Third Department of Internal Medicine, Interdisciplinary Graduate School of Medicine and Engineering, University of Yamanashi, Chuo City, \\ Yamanashi 409-3898, Japan \\ (Correspondence should be addressed to T Endo; Email: endot@yamanashi.ac.jp) \\ *(T Endo and T Kobayashi contributed equally to this work)
}

\begin{abstract}
We immunized AKR/N mice with bovine thyroglobulin (Tg) once every 2 weeks and monitored their timedependent changes in ${ }^{125} \mathrm{I}$ uptake activity in the thyroid glands. After 3 months, anti-Tg antibody was positive in all sera from the immunized mice. Serum free tri-iodothyronine $\left(\mathrm{T}_{3}\right)$ and free thyroxine $\left(\mathrm{T}_{4}\right)$ levels in the immunized mice $(n=6)$ were significantly higher than those in the saline injected (control) mice $(n=6)$. Neck counts as well as scintigraphy of the thyroid glands revealed that iodide uptake activity of the immunized mice was not suppressed, but was instead higher than that of the control mice. Two of the six immunized mice showed extremely high iodide uptake activity. The thyroid glands of these two mice were diffusely enlarged and the height of the epithelial cells was also
\end{abstract}

increased. In addition, two mice with high iodide uptake activity produced a high titer of thyroid-stimulating antibody. Additional experiments showed that 4 out of 11 AKR/N mice and 3 out of 10 C57BL6 mice immunized with Tg had high serum free $T_{3} /$ free $T_{4}$ levels, high ${ }^{125}$ I uptake activity of the thyroid, and positive thyroid-stimulating antibody activity. Diffuse goiter, thyrotoxicosis, high iodide uptake activity, and positive thyroid-stimulating antibody are the characteristics of Graves' disease. Thus, these mice exhibit the symptoms of Graves' disease. These results suggest that immunization with $\mathrm{Tg}$ induces Graves'-like disease in mice and that our methods will provide a new animal model of Graves' disease.

Journal of Endocrinology (2009) 202, 217-222

\section{Introduction}

Both Graves' disease and chronic autoimmune thyroiditis belong to the family of autoimmune thyroid diseases. However, Graves' disease may precede or follow chronic autoimmune thyroiditis in the same patient, presumably related by similar autoimmune processes (Kasagi et al. 1993).

Chronic autoimmune thyroiditis is characterized by serum autoantibodies against thyroglobulin $(\mathrm{Tg})$ and thyroid peroxidase (TPO), and histologically by fibrosis and varying degrees of lymphocytic infiltration in the thyroid (Dayan \& Daniels 1996). The appearance of MHC class II molecules on thyroid cells which has been correlated with $\gamma$-interferoncontaining T cells (Bottazzo et al. 1983), has been thought to be the initiating factor in chronic autoimmune thyroiditis (Hamilton et al. 1991). Patients with Graves' disease also produce autoantibodies against $\mathrm{Tg}$ and TPO, and the disease is characterized by thyroid-stimulating autoantibody (TSAb) against thyrotropin receptor (TSHR). This functional autoantibody stimulates hormone synthesis, secretion, and cell growth, and induces thyrotoxicosis and goiter in the disease (Kohn \& Shifrin 1982). However, the precise mechanisms in which TSHR peptides are presented as antigens still remain unclear.
Shimojo et al. (1996) succeeded in producing a mouse model of Graves' disease by immunization with fibroblasts expressing both TSHR and MHC class II molecules, after they clearly demonstrated that co-expression of MHC class II molecule and TSHR on the cell surface were necessary for producing TSAb in AKR/N mice. Therefore, clarification of the conditions or the environments that induce aberrant expression of MHC class II molecules in the antigenpresenting cells are important for understanding the pathogenesis of Graves' disease.

We hypothesize here that pathological conditions such as autoimmune thyroiditis and lymphocytic infiltration in thyroid glands must precede the production of TSAb. Thus, we have produced experimental autoimmune thyroiditis in mice by immunizing them with $\mathrm{Tg}$ and we monitored the iodide uptake activity of their thyroid glands. We found that some of them exhibited the symptoms of Graves' disease.

\section{Materials and methods}

\section{Animals and immunization with $\mathrm{Tg}$}

All studies performed were approved by the Animal Research Committee, Yamanashi University. Female AKR/N mice and C57BL6 mice were obtained from CLEA Japan, Inc., 
Tokyo, Japan. All mice were specific pathogen free and checked for pathogens once every 2 months. All mice were 12-14 weeks old at the beginning of the experiments. Bovine $\operatorname{Tg}(0.5 \mathrm{mg} / \mathrm{ml})$ purchased from Sigma-Aldrich Chemical Co. or saline was emulsified with the same volume of complete Freund's adjuvant (Wako Chemical Co., Tokyo, Japan) and then $50 \mu \mathrm{l}$ emulsion ( $25 \mu \mathrm{g}$ of $\mathrm{Tg} /$ mouse) was injected into the soleus muscle once every 2 weeks.

All immunizations were performed in the presence of complete Freund's adjuvant.

\section{${ }^{125}$ I uptake and measurement of thyroid hormones}

${ }^{125} \mathrm{I}-\mathrm{Na}(3 \cdot 7 \mathrm{GBq} / \mathrm{ml})$ was obtained from GE Healthcare, Japan. The solution was at first diluted with sterile saline to $9 \cdot 25 \times 10^{4} \mathrm{~Bq} / 100 \mu \mathrm{l}$. In experiment $1,100 \mu \mathrm{l}$ of this diluted solution was administrated into the peritoneal space at 1-3 months after the first immunization. After $24 \mathrm{~h}$, the mice were anesthetized with pentobarbital and the iodide uptake into the thyroid glands was monitored by neck counter and scintigraphy. In experiments 2 and 3, we did not carry out the monitoring of thyroid iodide uptake activities. At 3 months after the first immunization, accurate radioactivity of the resected thyrotracheal unit was also measured with a gamma-counter (Aloka, Autowell Gamma System, Model ARC-380, Tokyo, Japan) in all experiments. Serum free thyroxine $\left(\mathrm{T}_{4}\right)$ and free tri-iodothyronine $\left(\mathrm{T}_{3}\right)$ levels were assayed by an ECLusis system (Roche Diagnostic Co).

\section{Detection of anti-Tg antibody and assay for thyroid-stimulating antibody activity}

Detection of antibody against $\mathrm{Tg}$ and TPO was carried out with a commercial detection kit (Cosmic Co., Tokyo, Japan). For measuring TSAb activity, mouse IgG was partially purified with polyethylene glycol and the activity was assayed using a commercial kit for TSAb (Yamasa Shoyu Co., Chiba, Japan). Thyroid-stimulating antibody activity (\%) was calculated as follows: (cAMP increase by test IgG/cAMP increase by control $\operatorname{IgG}) \times 100$, as previously described (Ohmori et al. 1991). The cut-off value was set as $180 \%$.

\section{Results}

We divided female AKR/N mice into three groups (experiment 1). The first group was non-treated $(n=6)$; the second group $(n=6)$ was immunized with bovine $\mathrm{Tg}$ and the third $(n=6)$ was injected with saline once every 2 weeks; the ${ }^{125} \mathrm{I}$ uptake activity of their thyroid glands was then measured by neck counts (Fig. 1a). At 1 month after the first immunization, no significant difference in iodide uptake activity was observed between these three groups. Although no significant difference in the mean uptake activity between the groups was found at 2 months, mouse No. 1 in the immunized group showed high iodide uptake activity and
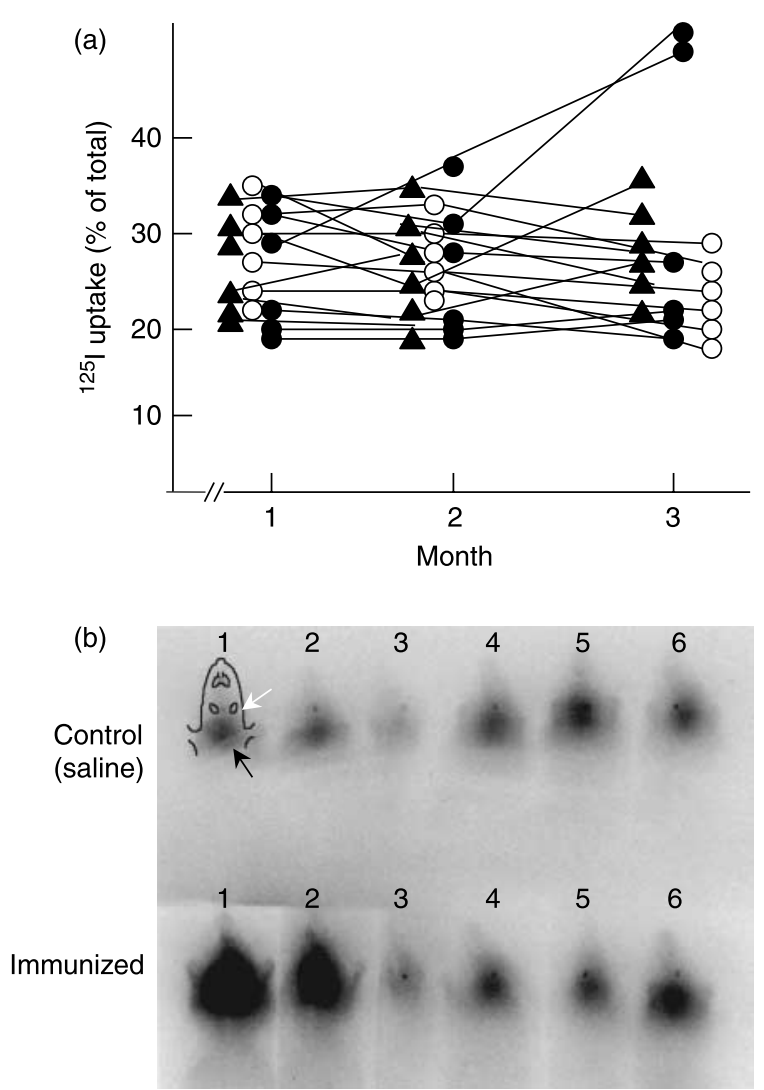

Figure $1{ }^{125}$ I uptake activity in mice immunized with thyroglobulin and control mice. (a) Time-dependent changes in ${ }^{125} I$ uptake activity in mice measured with neck counts. ${ }^{125}$ I-Na was administered into the peritoneal space of the non-treated mice (triangles), thyroglobulin immunized mice (filled circles) and the saline injected mice (open circles), and after $24 \mathrm{~h}$, the radioactivity was monitored by neck counts. The activity was indicated as a percentage of the total counts administered. (b) Scintigraphy of the thyroid glands was carried out 3 months after the first immunization. ${ }^{125} \mathrm{I}-\mathrm{Na}$ was administered to mice in the same way as in (a). After $24 \mathrm{~h}$, mice were exposed to the imaging plate for $1 \mathrm{~min}$ and the images were then analyzed using BAS 2500 systems (Fujix, Tokyo, Japan). Upper six thyroid images (Nos 1-6) were those of the control (saline injected) mice, and the lower six images (Nos 1-6) were those of the Tg immunized mice. White and black arrows indicate the location of submandibular glands and thyroid glands respectively.

this gradually increased. At 3 months, two out of six mice immunized with $\mathrm{Tg}$ showed higher iodide uptake activity than those of the other four mice in the same group. Thyroid scintigraphy carried out at that time also demonstrated that ${ }^{125} \mathrm{I}$ uptake activity of the thyroid glands in mice No. 1 and No. 2 in the Tg immunized group was higher than those of the other four mice of the same group and also higher than those of the non-treated or saline injected mice (Fig. 1b).

Three months after the first immunization, we examined their thyroid functions, histology of the glands, and presence of autoantibodies in the sera. Table 1 shows the radioiodide 
counts of the resected thyrotracheal units measured by a gamma counter. The mean iodide uptake of the immunized mice was significantly higher than that of the non-treated or saline-injected mice $(P<0 \cdot 05)$. Particularly, radioactivities from mice No. 1 and No. 2 in the immunized group were extremely high $\left(4 \cdot 72 \times 10^{6}\right.$ and $4.82 \times 10^{6}$ c.p.m). Figure $2 \mathrm{a}$ shows that those thyroid glands having high iodide uptake activity were diffusely enlarged compared with those of the saline-injected mice. Microscopic examination of the tissues revealed that the height of the epithelial cells in mice No. 1 and No. 2 was increased, as shown in Fig. 2c, which is a characteristic feature of Graves' disease. When we compared the mean height of 500 epithelial cells from the immunized mice with that of 500 cells from the saline-injected mice, the former $(6.58 \pm 0.08 \mu \mathrm{m})$ was significantly taller than the latter (3.03 $\pm 0.08 \mu \mathrm{m}$; Fig. 2e). No prominent lymphocyte infiltration was observed among the tissues. The mean serum free $T_{3}$ and free $T_{4}$ levels of the immunized mice were significantly $(P<0 \cdot 001)$ higher than those of the saline-injected mice (Fig. 3). The free $\mathrm{T}_{3}$ levels in mice No. 1 and No. 2 were markedly higher than those of the other four mice in the Tg immunized group (Fig. 3 and Table 1). All $\mathrm{Tg}$ immunized mice produced anti-Tg antibody in their sera, but no activity was observed in the non-treated and the saline-injected mice. None of the mice produced anti-TPO antibody in their sera (Table 1). Interestingly, the TSAb values produced by mice No. 1 and No. 2 were 1320 and $391 \%$ respectively (Table 1 ).

Additionally, we immunized 11 AKR/N mice with bovine $\mathrm{Tg}$, and 3 months later, measured their serum free $\mathrm{T}_{3}$ and free
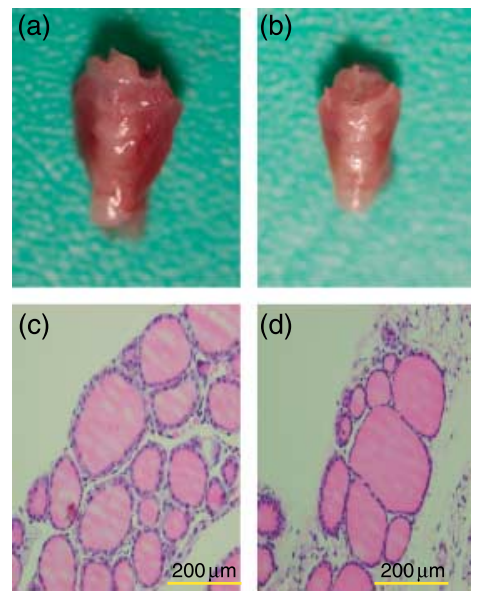

(e)

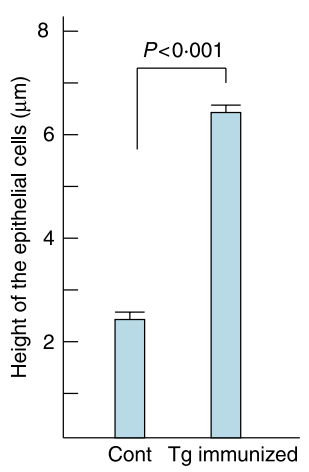

Figure 2 Morphological changes of the thyroid glands of mice immunized with thyroglobulin. (a) Thyroid glands of a mouse immunized with thyroglobulin (Tg1) are diffusely enlarged.

(b) Control (saline injected) mouse (S1). (c and d) Hematoxylin-eosin staining of the sections from the immunized mouse $(\operatorname{Tg} 1)(\mathrm{c}, \times 100)$ and the control mouse $(S 1)(d, \times 100)$. (e) Height of epithelial cells of the immunized mice with that of the control mice. The heights of 500 epithelial cells from control mice and those from immunized mice were measured after amplifying their digital images. Statistical analysis was carried out with the Student's $t$-test.
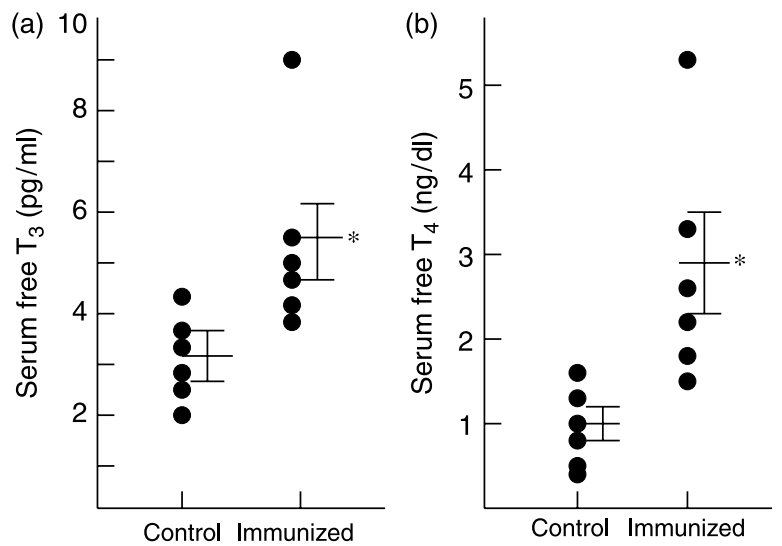

Figure 3 Serum free $T_{3}$ and free $T_{4}$ levels in mice immunized with thyroglobulin and saline injected (control) mice. At 3 months after the first immunization, the sera were obtained by heart puncture and the free $T_{3}$ (a) and free $T_{4}$ (b) levels were determined as described in the Materials and methods section. The values are indicated as mean \pm S.E.M. $* P<0 \cdot 05$.

$\mathrm{T}_{4}$ levels, ${ }^{125} \mathrm{I}$ uptake activity in the thyroid glands, and TSAb activity (experiment 2). In this experiment, we omitted monitoring of thyroid iodide uptake activities of mice by neck counter, so we did not administer ${ }^{125} \mathrm{I}$ at 1 and 2 months after the first immunization. The mean serum free $T_{3}$ and free $T_{4}$ levels from immunized mice were significantly higher than those of the control mice. The mean ${ }^{125} \mathrm{I}$ uptake activity in the thyroid glands of the immunized mice $(3 \cdot 68$ $\pm 0.20 \times 10^{6}$ c.p.m.) was not suppressed, but was instead higher than that of the control mice $\left(1 \cdot 99 \pm 0.08 \times 10^{6}\right.$ c.p.m). We also observed that 4 out of the 11 immunized mice with a high serum free $T_{3}$ level $(\operatorname{Tg} 4,6,8$, and 11) possessed high TSAb activity (Table 1).

To know whether our observation is specific to the AKR/N strain, we immunized C57BL6 mice $(n=10)$ with bovine $\mathrm{Tg}$ using the same protocol (experiment 3 ). Again, we obtained the results that mean serum free $T_{3}$ and free $T_{4}$ levels and mean ${ }^{125} \mathrm{I}$ uptake activity in the thyroid glands of the immunized mice were significantly higher than those of the control mice (Table 1). Mice with high serum free $T_{3}$ and free $\mathrm{T}_{4}$ levels exhibited high TSAb activity ( $\operatorname{Tg} 2,5$, and 6), suggesting that immunization with Tg also produce Graves'like disease in C57BL6 mice.

\section{Discussion}

There exists a consensus that TSAb plays a central role in the pathogenesis of Graves' disease. The autoantibody stimulates thyroid epithelial cells like TSH and induces thyrotoxicosis and goiter (Shimojo et al. 1996). We previously reported the expression of TSHR in fat cells, the level of which is almost comparable with that in the thyroid (Endo et al. 1995). 
Table 1 Thyroid functions of mice immunized with thyroglobulin and control mice

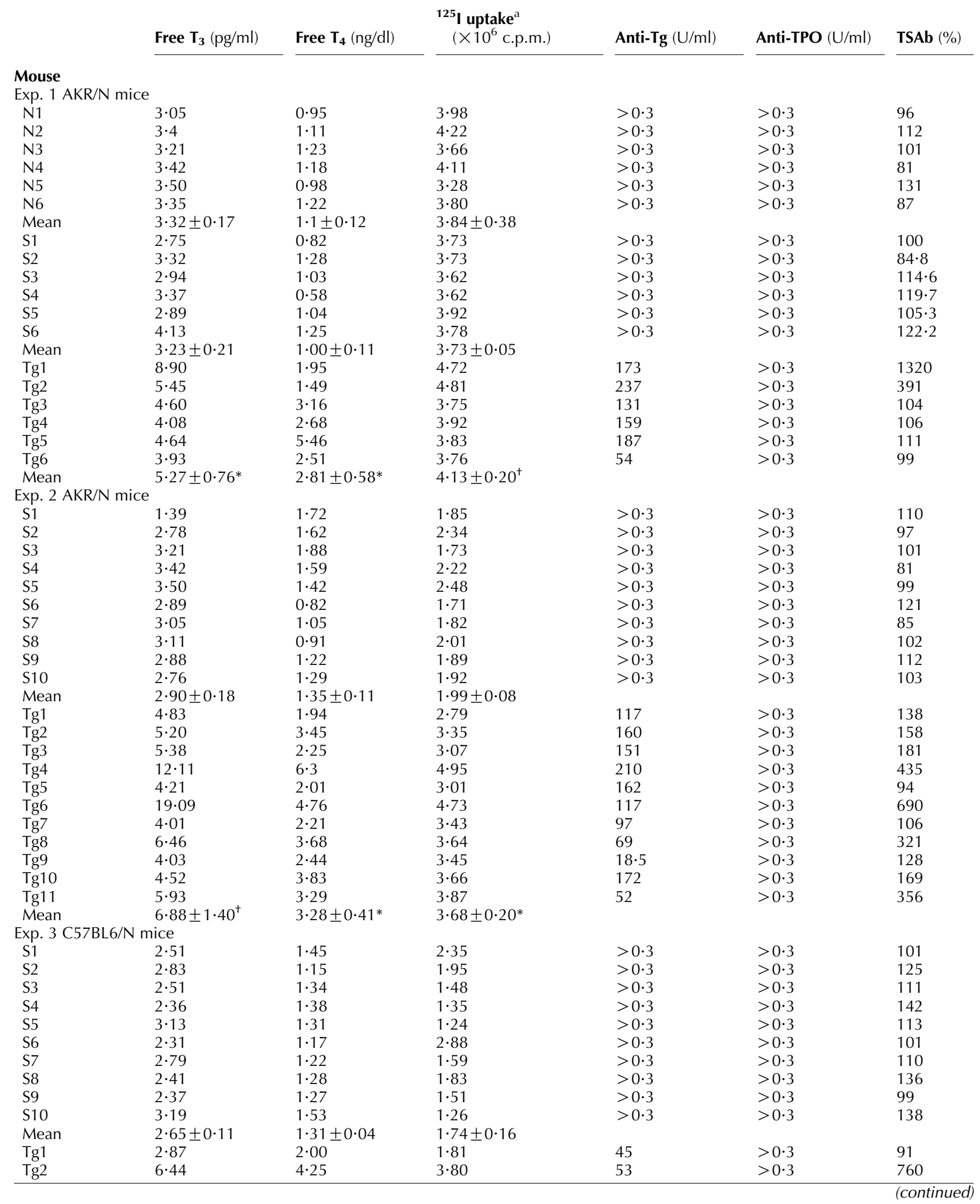


Table 1 Continued

\begin{tabular}{|c|c|c|c|c|c|c|}
\hline & Free $\mathbf{T}_{\mathbf{3}}(\mathrm{pg} / \mathrm{ml})$ & Free $\mathbf{T}_{\mathbf{4}}(\mathrm{ng} / \mathrm{dl})$ & $\begin{array}{l}{ }^{125} \text { I uptake }{ }^{a} \\
\quad\left(\times 10^{6} \text { c.p.m. }\right)\end{array}$ & Anti-Tg (U/ml) & Anti-TPO (U/ml) & TSAb $(\%)$ \\
\hline Tg3 & $3 \cdot 33$ & $2 \cdot 11$ & $1 \cdot 76$ & 30 & $>0 \cdot 3$ & 177 \\
\hline Tg4 & $3 \cdot 03$ & $1 \cdot 75$ & $2 \cdot 94$ & 33 & $>0 \cdot 3$ & 161 \\
\hline Tg5 & $6 \cdot 28$ & $2 \cdot 21$ & 3.95 & 37 & $>0 \cdot 3$ & 381 \\
\hline Tg6 & $12 \cdot 05$ & $3 \cdot 61$ & $4 \cdot 34$ & 207 & $>0 \cdot 3$ & 654 \\
\hline Tg7 & $3 \cdot 14$ & $3 \cdot 22$ & $2 \cdot 38$ & 39 & $>0 \cdot 3$ & 83 \\
\hline Tg8 & $3 \cdot 39$ & $3 \cdot 38$ & $2 \cdot 31$ & 44 & $>0 \cdot 3$ & 118 \\
\hline Tg9 & $4 \cdot 40$ & $2 \cdot 07$ & $2 \cdot 26$ & 69 & $>0 \cdot 3$ & 113 \\
\hline Tg10 & $2 \cdot 31$ & $1 \cdot 51$ & $1 \cdot 73$ & $2 \cdot 7$ & $>0 \cdot 3$ & 101 \\
\hline Mean & $4 \cdot 72 \pm 0.93^{*}$ & $2 \cdot 61 \pm 0 \cdot 29^{\dagger}$ & $2 \cdot 73 \pm 0 \cdot 30^{*}$ & & & \\
\hline
\end{tabular}

$\mathrm{N}$, non-treated mice; $\mathrm{S}$, control (saline) mice; $\mathrm{Tg}$, thyroglobulin immunized mice. ${ }^{*} P<0 \cdot 001$ versus control (saline) mice. ${ }^{+} P<0 \cdot 05$ versus control (saline) mice. a Radioactivity of the thyro-tracheal unit measured by a gamma counter.

The development of exophthalmos and pretibial myxedema is attributable to the autoantibody against TSHR.

Recently, many groups have developed animal models of Graves' disease by immunizing with TSHR peptides (Endo et al. 1991), TSHR protein (Kaithamana et al. 1999), or TSHR-expressing fibroblasts (Shimojo et al. 1996), or by using the expression plasmid of TSHR (Costagliola et al. 2000) and adenovirus-mediated TSHR (Nagayama et al. 2002). All of these data support that TSHR autoantibody is the cause of Graves' disease. Thus, our next concern was the antigen-presenting mechanism of TSHR in its autoimmune process. From this point of view, Shimojo's model is extremely important, because the co-existence of $\mathrm{MHC}$ class II molecules and TSHR on the cell surface of fibroblasts can produce TSAb in mice, but not the co-existence of $\mathrm{MHC}$ class I molecules and TSHR. The evidence supports the previous hypothesis that aberrant expression of MHC class II molecule on thyroid epithelial cells may trigger a cascade of self-directed, uncontrolled immune response in Graves' disease (Hanafusa et al. 1983).

However, it is still controversial whether TSHR peptides are presented as antigens by specifically antigen-presenting cells (macrophages) or by other cells (thyroid epithelial cells). In the former, destructive or degenerative changes of thyroid epithelial cells may precede the process, and in case of the latter, infiltration of $\gamma$-interferon containing $\mathrm{T}$ cells may precede the process.

Twarog \& Rose (1968) produced experimental autoimmune thyroiditis in mice by immunizing mice with thyroid extracts emulsified with Freund's complete adjuvant. After that, this disease has been readily induced in many strains of mice by immunization with mouse Tg emulsified in Freund's complete adjuvant. In some strains (low responders to $\mathrm{Tg}$ ), there is only minor thyroid damage after immunization with $\mathrm{Tg}$, whereas in other strains (high responders), the thyroid damage is extensive (Vladutiu \& Rose 1971). It is widely believed that these mouse models of autoimmune thyroiditis are in a hypothyroid state, but there are few studies of thyroid function in mice with induced autoimmune thyroiditis.
Vladutiu \& Kenney (1985) investigated the thyroid function of mice immunized with $\mathrm{Tg}$. They found that in all mice (low and high responders), the lowest levels of $\mathrm{T}_{4}$ were observed 2 weeks after immunization, and in the fourth week, $\mathrm{T}_{4}$ concentration was, surprisingly and inexplicably, higher than the pre-immunization values. We demonstrate here that immunization of mice with $\mathrm{Tg}$ induces thyrotoxicosis. A detailed comparison of our data with that of Vladutiu \& Kenney is difficult because their experimental conditions and protocols were different from ours, but thyrotoxicosis might occur after 4 weeks from the first immunization with $\mathrm{Tg}$.

However, iodide uptake activity of $\mathrm{Tg}$ immunized mice was not suppressed, but was instead enhanced, so it is unlikely that the increase of serum thyroid hormone levels was merely due to the destruction of thyroid epithelial cells. The phenomenon was observed not only in AKR/N mice (high responders) but also in C57BL6 mice (low responders), suggesting that it is not strain specific. In addition, some of the $\mathrm{Tg}$ immunized AKR/N mice as well as C57BL6 mice had high iodide uptake activity and high titers of TSAb.

To obtain clear thyroid image with short exposure time to the imaging plate, we administrated $9.25 \times 10^{4} \mathrm{~Bq}$ of ${ }^{125} \mathrm{I}$ to each mouse in experiment 1 , the dose $(4.6 \mathrm{MBq} / \mathrm{kg})$ of which is almost comparable with that used for therapy for Graves' disease in human. Recently, it has been reported that $\mathrm{TSAb}$ may occur shortly after radioiodine therapy in toxic multinodular goiter, in which pre-existing autoimmunity may not be a requirement for the induction of the antibodies (Hovens et al. 2007). So the possibility remains that administration of ${ }^{125} \mathrm{I}$ to mice in the course of experiment 1 might induce TSAb in these mice. However, in experiments 2 and 3, we omitted monitoring of thyroid iodide uptake activities by neck counter so, we administrated ${ }^{125}$ I to the animals only at 3 months point. Thus, we think it likely that Graves'-like disease in these mice was induced by immunization of $\mathrm{Tg}$. It would be important to know whether immunization with other thyroid antigens such as TPO also 
induce Graves' like disease in mice. However, our results suggest that immunization with $\mathrm{Tg}$ induces Graves'-like disease in mice and also that the pathogenesis of two disorders are closely related.

\section{Declaration of interest}

The authors declare no conflict of interest.

\section{Funding}

This research received funding from the Basic Research Fund (C) of the Ministry of Education, culture, sports, Japan (Grant number 21591127) to TE.

\section{References}

Bottazzo GF, Pujol-Borrell R, Hanafusa T \& Feldmann M 1983 Role of aberrant HLA-DR expression and antigen presentation in induction of endocrine autoimmunity. Lancet 2 1115-1119.

Costagliola S, Many MC, Denef JF, Pohlenz J, Refetoff S \& Vassart G 2000 Genetic immunization of outbred mice with thyrotropin receptor cDNA provides a model of Graves' disease. Journal of Clinical Investigation 105 803-811.

Dayan CM \& Daniels GH 1996 Chronic autoimmune thyroiditis. New England Journal of Medicine 335 99-107.

Endo T, Ohmori M, Ikeda M \& Onaya T 1991 Thyroid stimulating activity of rabbit antibodies toward the human thyrotropin receptor peptide. Biochemical and Biophysical Research Communications 177 145-150.

Endo T, Ohta K, Haraguchi K \& Onaya T 1995 Cloning and functional expression of a thyrotropin receptor cDNA from rat fat cells. Journal of Biological Chemistry 270 10833-10837.

Hamilton F, Black M, Farquharson MA, Stewart C \& Foulis AK 1991 Spatial correlation between thyroid epithelial cells expressing class II MHC molecules and interferon-gamma-containing lymphocytes in human thyroid autoimmune disease. Clinical and Experimental Immunology $\mathbf{8 3}$ 64-68.
Hanafusa T, Pujol-Borrell R, Chiovato L, Russell RC, Doniach D \& Bottazzo GF 1983 Aberrant expression of HLA-DR antigen on thyrocytes in Graves' disease: relevance for autoimmunity. Lancet 2 1111-1115.

Hovens GC, Heemstra KA, Buiting AM, Stokkel MP, Karperien M, Ballieux BE, Pereira AM, Romijn JA \& Smit JW 2007 Induction of stimulating thyrotropin receptor antibodies after radioiodine therapy for toxic multinodular goitre and Graves' disease measured with a novel bioassay. Nuclear Medicine Communications 28 123-127.

Kaithamana S, Fan J, Osuga Y, Liang SG \& Prabhakar BS 1999 Induction of experimental autoimmune Graves' disease in BALB/c mice. Journal of Immunology 163 5157-5164.

Kasagi K, Hidaka A, Nakamura H, Takeuchi R, Misaki T, Iida Y \& Konishi J 1993 Thyrotropin receptor antibodies in hypothyroid Graves' disease. Journal of Clinical Endocrinology and Metabolism 76 504-508.

Kohn LD \& Shifrin S 1982 Receptor structure and function: an exploratory approach using the thyrotropin receptor as a vehicle. Horizons in Biochemistry and Biophysics 6 1-42.

Nagayama Y, Kita-Furuyama M, Ando T, Nakao K, Mizuguchi H, Hayakawa T, Eguchi K \& Niwa M 2002 A novel murine model of Graves' hyperthyroidism with intramuscular injection of adenovirus expressing the thyrotropin receptor. Journal of Immunology 168 2789-2794.

Ohmori M, Endo T \& Onaya T 1991 Development of chicken antibodies toward the human thyrotropin receptor peptides and their bioactivities. Biochemical and Biophysical Research Communications 174 399-403.

Shimojo N, Kohno Y, Yamaguchi K, Kikuoka S, Hoshioka A, Niimi H, Hirai A, Tamura Y, Saito Y, Kohn LD et al. 1996 Induction of Graveslike disease in mice by immunization with fibroblasts transfected with the thyrotropin receptor and a class II molecule. PNAS 93 11074-11079.

Twarog FJ \& Rose NR 1968 The production of thyroid autoantibodies in mice. Journal of Immunology 101 242-250.

Vladutiu AO \& Kenney EM 1985 Thyroid function in mice with experimental autoimmune thyroiditis. Clinical and Experimental Immunology $61264-275$.

Vladutiu AO \& Rose NR 1971 Autoimmune thyroiditis: correlation with histocompatibility (H-2) type. Science 1741137.

Received in final form 18 May 2009

Accepted 2 June 2009

Made available online as an Accepted Preprint 2 June 2009 